\title{
Associations of serious mental illness with earnings: results from the WHO World Mental Health surveys
}

Daphna Levinson, Matthew D. Lakoma, Maria Petukhova, Michael Schoenbaum, Alan M. Zaslavsky, Matthias Angermeyer, Guilherme Borges, Ronny Bruffaerts, Giovanni de Girolamo, Ron de Graaf, Oye Gureje, Josep Maria Haro, Chiyi Hu, Aimee N. Karam, Norito Kawakami, Sing Lee, Jean-Pierre Lepine, Mark Oakley Browne, Michail Okoliyski, José Posada-Villa, Rajesh Sagar, Maria Carmen Viana, David R. Williams and Ronald C. Kessler

\section{Background}

Burden-of-illness data, which are often used in setting healthcare policy-spending priorities, are unavailable for mental disorders in most countries.

\section{Aims}

To examine one central aspect of illness burden, the association of serious mental illness with earnings, in the World Health Organization (WHO) World Mental Health (WMH) Surveys.

\section{Method}

The WMH Surveys were carried out in 10 high-income and 9 low- and middle-income countries. The associations of personal earnings with serious mental illness were estimated.

\section{Results}

Respondents with serious mental illness earned on average a third less than median earnings, with no significant betweencountry differences $\left(\chi^{2}(9)=5.5-8.1, P=0.52-0.79\right)$. These losses are equivalent to $0.3-0.8 \%$ of total national earnings. Reduced earnings among those with earnings and the increased probability of not earning are both important components of these associations.

\section{Conclusions}

These results add to a growing body of evidence that menta disorders have high societal costs. Decisions about healthcare resource allocation should take these costs into consideration.

\section{Declaration of interest}

R.C.K. has been a consultant for GlaxoSmithKline, Kaiser Permanente, Pfizer, Sanofi-Aventis, Shire Pharmaceuticals and Wyeth-Ayerst; has served on advisory boards for Eli Lilly \& Company and Wyeth-Ayerst; and has had research support for his epidemiological studies from Bristol-Myers Squibb, El Lilly \& Company, GlaxoSmithKline, Johnson \& Johnson Pharmaceuticals, Ortho-McNeil Pharmaceuticalsc, Pfizer and Sanofi-Aventis.
The fact that mental disorders are associated with high societal burden is now well established both in terms of disability-adjusted life-years ${ }^{1}$ and as a fraction of national budgets. ${ }^{2}$ A large part of this burden consists of indirect costs such as those associated with reduced rates of labour force participation, ${ }^{3}$ unemployment among those in the labour force ${ }^{4}$ and underemployment among those who are employed. ${ }^{5}$ Mental disorders also have costs for employers, including high rates of sporadic absenteeism ${ }^{6}$ and disability-related work leave ${ }^{7}$ as well as low levels of on-the-job work performance. ${ }^{8}$ The most commonly used approach to study these labour market costs is the human capital approach. ${ }^{9}$ This approach is based on the observation that wages and salaries are paid in direct return for productive services, making earnings a good indicator of the human capital accumulated by the individual and making earnings-equivalent time forgone because of an illness a good representation of the indirect costs of that illness to the employer. Although a considerable body of empirical research has used the human capital approach to document adverse societal effects of mental disorders, this research has been carried out largely in a small number of high-income countries. ${ }^{4,7}$ Yet epidemiological data show that mental disorders are common throughout the world. ${ }^{10}$ The purpose of the current paper is to use the survey data in the World Health Organization (WHO) World Mental Health (WMH) Surveys to make estimates of the human capital costs of mental disorders in a wider range of countries (population samples from 10 high-income and 9 low- and middle-income countries with a total of more than 100000 respondents). We focus on serious mental illness because previous research has shown that earnings and long-term work incapacity are both much more strongly related to serious mental illness than to less serious forms of mental illness. ${ }^{5,11}$

\section{Method}

\section{Sample}

Twenty surveys were carried out in 19 countries in the Americas (Brazil, Colombia, Mexico, USA), Europe (Belgium, Bulgaria, France, Germany, Italy, The Netherlands, Spain), the Middle East (Israel, Lebanon), Africa (Nigeria, South Africa), Asia (Japan, People's Republic of China: Beijing, Shanghai, Shenzhen, India: Pondicherry), and New Zealand (online Table DS1). The World Bank $^{12}$ classifies Brazil, Bulgaria, Colombia, India, Lebanon, Mexico, Nigeria, the People's Republic of China, and South Africa as low- and middle-income countries, and all the other surveyed countries as high-income countries. All surveys were based on either multistage clustered area probability samples of households, with one or two random respondents selected in each sample household, or multistage clustered area probability samples of individuals listed in a national population register. All interviews were carried out face to face by trained lay interviewers.

Recruitment began with a letter sent to the households of potential respondents describing the purpose of the study and answering commonly asked questions about how their household was selected, the voluntary nature of participation and the confidentiality of responses. Interviewers reviewed these issues with the potential respondents when they visited the households 
and obtained informed consent before beginning the interviews. Standard procedures for recording and storing the survey data in de-identified files were used to protect the confidentiality of respondents. A respondent safety plan was developed separately in each country consistent with local norms to address concerns about evidence of respondent danger to self or others. These recruitment, consent and respondent protection procedures were approved by the Human Subjects Committee of the lead organisation that carried out the survey in each country.

The total sample size was 101825 , with individual country sample sizes ranging from a low of 2372 in The Netherlands to a high of 12992 in New Zealand. The weighted average response rate across countries was $72.2 \%$. Internal subsampling was used to reduce respondent burden by dividing the interview into two parts. Part I included the core diagnostic assessment of mental disorders. Part II included a detailed risk-factor questionnaire, a series of diagnoses of secondary interest, and a series of questions about the correlates of mental illness. Earnings were assessed in Part II. All respondents completed Part I $(n=101825)$, and all respondents who met criteria for any Part I mental disorder plus a probability sample of other Part I respondents were administered Part II $(n=51007)$. (All respondents were administered Part II in Israel and South Africa.) The Part I data were weighted to adjust for differential probabilities of selection and for the undersampling of hard-to-reach respondents (a probability subsample of whom received special intensive recruitment efforts). The Part II data were additionally weighted to adjust for the undersampling of Part I respondents without a core disorder (i.e. weighting by the inverse of probability of selection into Part II) to remove any bias in Part II relative to Part I. A final Part II was weight adjusted for discrepancies between the sample distributions and the population census on a wide range of sociodemographic and geographic variables. The analyses reported here were based on the respondents in the weighted Part II sample who were of working age, which we defined for purposes of this analysis as 18-64 years of age $(n=44561)$. A more detailed description of WMH sampling that includes an analysis of the effects of weights and weight trimming is presented elsewhere. ${ }^{13}$

\section{Interviewer training and fieldwork quality control}

Each WMH interviewer was required to complete a 7-day training course and to pass an examination that included administering a series of practice interviews with scripted responses before beginning production work. During production, supervisors reviewed all interviews for completeness and made follow-up contacts with a random $5-10 \%$ of respondents to confirm household addresses, household enumeration, random selection procedures and the length of the interview. Supervisors repeated a random sample of questions during these interview audits in order to make sure interviewers administered the complete interview and that responses were recorded accurately. In addition, aggregate interviewer-level data were monitored on an ongoing basis to look for distinctive interviewer-specific data patterns that might indicate fabrication of data. A more detailed discussion of interviewer training and field quality-control procedures is presented elsewhere. ${ }^{14}$

\section{Measures}

\section{Mental illness}

All surveys assessed mental illness with the WHO Composite International Diagnostic Interview (CIDI), ${ }^{15}$ a fully-structured diagnostic interview that assesses the prevalence of mental disorders according to the definitions and criteria of both the DSM-IV ${ }^{16}$ and ICD-10 17 diagnostic systems. The DSM-IV criteria were used in the current report. We focused on prevalence at any time within the 12 months before the interview. The disorders considered include anxiety disorders (generalised anxiety disorder, panic disorder, phobias, post-traumatic stress disorder) and mood disorders (major depressive disorder, dysthymic disorder, bipolar disorder). In making diagnosis, CIDI organic exclusion rules were imposed. Clinical reappraisal studies carried out in conjunction with a number of WMH surveys using the Structured Clinical Interview for DSM-IV ${ }^{18}$ as the gold standard documented generally good concordance of masked clinical diagnoses with diagnoses based on the CIDI. Serious mental illness was defined following previous WMH analyses ${ }^{19}$ as either meeting criteria for bipolar I disorder or having any other 12-month diagnosis with evidence of serious role impairment. Serious role impairment was defined as either having a score in the severe range on one or more of the Sheehan Disability Scales, ${ }^{20}$ which assess disability in work-role performance, household maintenance, social life or intimate relationships or attempting suicide. The CIDI also assessed DSM-IV alcohol and illicit drug use with or without dependence. Both lifetime prevalence of these conditions and prevalence in the 12 months before the interview were used as controls to adjust for comorbidity between mental and substance disorders. Other 12-month disorders that did not meet criteria for serious mental illness were not considered because preliminary analysis found that they are not significantly related to earnings. (Detailed results are available from the authors on request.)

\section{Earnings}

All Part II respondents were asked to report their personal earnings in the past 12 months before taxes. Respondents were instructed to count only wages and other stipends from employment, not pensions, investments or other financial assistance or income. As in most community surveys, the item-level non-response rate for this question was non-trivial (with a range of $0.8-18.3 \%$ and an interquartile range of $2.2-7.0 \%$ across surveys). Mean imputation was used to impute missing values. It is noteworthy that serious mental illness was not significantly related to having a missing value on the earnings variable either in high- or low- and middle-income countries $\left(\chi^{2}(1)=0.1-3.1\right.$, $P=0.08-0.71)$. This means that the decision about how to deal with these missing values (i.e. either by case deletion, imputation or introducing a control variable for having a missing value on this variable into the regression equations) would not meaningfully influence the magnitude of the serious mental illness coefficients in the regression analyses reported below.

\section{Analysis methods}

In order to facilitate pooling of results across countries, earnings reports were divided by the median earnings in the country. These transformed scores were then used as outcomes in pooled regression analyses estimated simultaneously across all countries. Prior to carrying out this analysis, earnings distributions were compared for respondents with and without serious mental illness. The earnings distributions among respondents with any earnings were divided for this purpose into four categories by defining low earnings as less than half the within-country median, low-average earnings as up to the median, high-average earnings as up to twice the median, and high earnings as greater than two times the median. 
The regression analyses were then carried out using a dummy variable for serious mental illness as the predictor of primary interest. The outcome was the transformed continuous earnings score. Control variables were included for sociodemographics (age, gender), country (19 dummy variables to distinguish respondents across the 20 surveys), substance disorders and interactions between gender and all other predictors. The gender interactions were included because previous research has shown that the predictors of earnings are different for males than females. ${ }^{5,21}$

A major statistical problem in estimating regression equations of this sort is that the earnings distribution is highly skewed, with a meaningful minority of the sample in each country reporting no earnings and a much higher proportion of other respondents having high earnings than would be found in a normal distribution. This makes ordinary least squares regression analysis both biased and inefficient. Economists have developed special statistical procedures to address this problem that involve using either two-part models (i.e. a first logistic regression model to predict having any earnings and a second linear regression model to predict amount of earnings among those with any earnings) ${ }^{22,23}$ or special one-part non-linear models. ${ }^{24,25}$ We used both approaches in addition to conventional ordinary least squares regression analysis (with linear, square root and logarithmic link functions) and selected the best approach based on standard empirical model comparison procedures. ${ }^{26}$ The details of the modelling approaches are discussed elsewhere, ${ }^{5}$ but the final best-fitting model was a one-part generalised linear model that assumed a logarithmic link function between predictors and the outcome with prediction error variance proportional to the predicted values.

As the best-fitting model used a non-linear transformation of the outcome in conjunction with an interaction between serious mental illness and gender, model-based simulation was needed to interpret the coefficients. This was done by predicting earnings twice for each respondent from the model coefficients, once using the actual characteristics of the respondent and a second time recoding all respondents with serious mental illness to assume that they did not have serious mental illness. Individual-level differences between these estimates were averaged across all respondents with serious mental illness to estimate the mean individual-level decrease in earnings associated with serious mental illness. Societal-level estimates were then obtained by multiplying this individual-level estimate by the prevalence of serious mental illness. Demographic rate standardisation ${ }^{27}$ was then used to decompose the societal-level estimates into components due to the associations of serious mental illness with probability of having any earnings and with the amount earned by those with any earnings. Because the WMH sample design featured weighting and clustering, the standard errors of the model coefficients and the simulated estimates were obtained using the design-based jackknife repeated replications method. ${ }^{28}$ In this method, each model and each simulation is replicated many times in pseudo-samples to generate a distribution of each coefficient that is then used to calculate an empirical estimate of the standard error of the coefficient. Multivariate significance was estimated using design-adjusted Wald $\chi^{2}$-tests. ${ }^{29}$ Statistical significance was consistently evaluated using two-sided tests at the 0.05 level of significance.

\section{Results}

\section{Sample distributions}

Consistent with their population distributions, the age distribution of the sample is different in high-income countries from that in low- and middle-income countries $\left(\chi^{2}(3)=553.1, P<0.001\right)$ (Table 1). Larger proportions of respondents are in the age ranges $18-24(24.5 \%$ v. $15.6 \%)$ and $25-39(40.8 \%$ v. $35.0 \%)$ in low- and middle-income than high-income countries, whereas larger proportions are in the age ranges $40-54(34.0 \%$ v. $24.8 \%)$ and $55-64(15.4 \%$ v. $10.0 \%)$ in high-income than low- and middleincome countries. Females have a somewhat older age distribution than males in low- and middle-income countries $\left(\chi^{2}(3)=9.2\right.$, $P=0.026)$, but there is no gender difference in the age distribution in high-income countries $\left(\chi^{2}(3)=1.3, P=0.74\right)$. Serious mental illness is estimated to be significantly more prevalent in highincome than low- and middle-income countries both in the total sample $(4.3 \%$ v. $3.0 \%, t=6.4, P<0.001)$ and separately among males $(3.5 \%$ v. $2.2 \%, t=5.1, P<0.001)$ and females $(5.0 \% v$. $3.9 \%, t=4.3, P<0.001$ ) (Table 1). Serious mental illness is estimated to be significantly more common among females than males in both high-income and low- and middle-income countries $(t=6.1-6.6, P<0.001)$.

\section{Earnings distributions among respondents with and without serious mental illness}

The proportion of respondents with non-zero earnings is significantly lower among those with than those without serious mental illness in both high-income $(61.9 \%$ v. $75.6 \%, t=8.6$,

Table 1 Distributions of age, gender and mental illness in high-income and low- and middle-income countries ${ }^{a}$

\begin{tabular}{|c|c|c|c|c|c|c|}
\hline & \multicolumn{6}{|c|}{$\%$ (s.e.) } \\
\hline & \multicolumn{3}{|c|}{ High-income countries } & \multicolumn{3}{|c|}{ Low- and middle-income countries } \\
\hline & Total $(n=23457)$ & Male $(n=10114)$ & Female $(n=13343)$ & Total $(n=21104)$ & Male $(n=9040)$ & Female $(n=12064)$ \\
\hline \multicolumn{7}{|l|}{ Age, years ${ }^{b}$} \\
\hline $18-24$ & $15.6(0.4)$ & $16.0(0.5)$ & $15.3(0.5)$ & $24.5(0.4)$ & $24.6(0.7)$ & $24.5(0.6)$ \\
\hline $25-39$ & $35.0(0.5)$ & $34.7(0.6)$ & $35.2(0.6)$ & $40.8(0.5)$ & $41.3(0.7)$ & $40.2(0.6)$ \\
\hline $40-54$ & $34.0(0.4)$ & $34.0(0.6)$ & $34.0(0.6)$ & $24.8(0.4)$ & $25.1(0.6)$ & $24.4(0.5)$ \\
\hline $55-64$ & $15.4(0.3)$ & $15.3(0.5)$ & $15.5(0.4)$ & $10.0(0.3)$ & $9.1(0.4)$ & $10.8(0.4)$ \\
\hline $\begin{array}{l}\text { 12-month serious } \\
\text { mental illness }\end{array}$ & $4.3(0.1)$ & $3.5(0.2)$ & $5.0(0.2)$ & $3.0(0.1)$ & $2.2(0.2)$ & $3.9(0.2)$ \\
\hline \multicolumn{7}{|c|}{$\begin{array}{l}\text { a. High-income countries: Belgium, France, Germany, Israel, Italy, Japan, The Netherlands, Spain, USA, New Zealand; low- and middle-income countries: South Africa, Brazil, Bulgaria } \\
\text { China, Colombia, Lebanon, Mexico, Nigeria, Pondicherry, Shenzhen. } \\
\text { b. Significance of age differences was evaluated with Wald design-based } \chi^{2} \text {-tests. The age distribution is significantly different between high-income and low-and middle-income } \\
\text { countries in the total sample }\left(\chi^{2}(3)=553.1, P<0.001\right) \text { and separately among males }\left(\chi^{2}(3)=272.5, P<0.001\right) \text { and females }\left(\chi^{2}(3)=298.4, P<0.001\right) \text {. Males and females also have } \\
\text { significantly different age distributions in low- and middle-income }\left(\chi^{2}(3)=9.2, P=0.026\right) \text { but not high-income }\left(\chi^{2}(3)=1.3, P=0.74\right) \text { countries. } \\
\text { c. The estimated prevalence of serious mental illness differs significantly between high-income and low- and middle-income countries in the total sample }\left(\chi^{2}(1)=40.4, P<0.001\right) \\
\text { and separately among males }\left(\chi^{2}(1)=25.0, P<0.001\right) \text { and females }\left(\chi^{2}(1)=17.6, P<0.001\right) \text {. Males and females also differ in prevalence of serious mental illness in both high-income } \\
\left(\chi^{2}(1)=34.7, P<0.001\right) \text { and low- and middle-income }\left(\chi^{2}(1)=39.8, P<0.001\right) \text { countries. }\end{array}$} \\
\hline
\end{tabular}




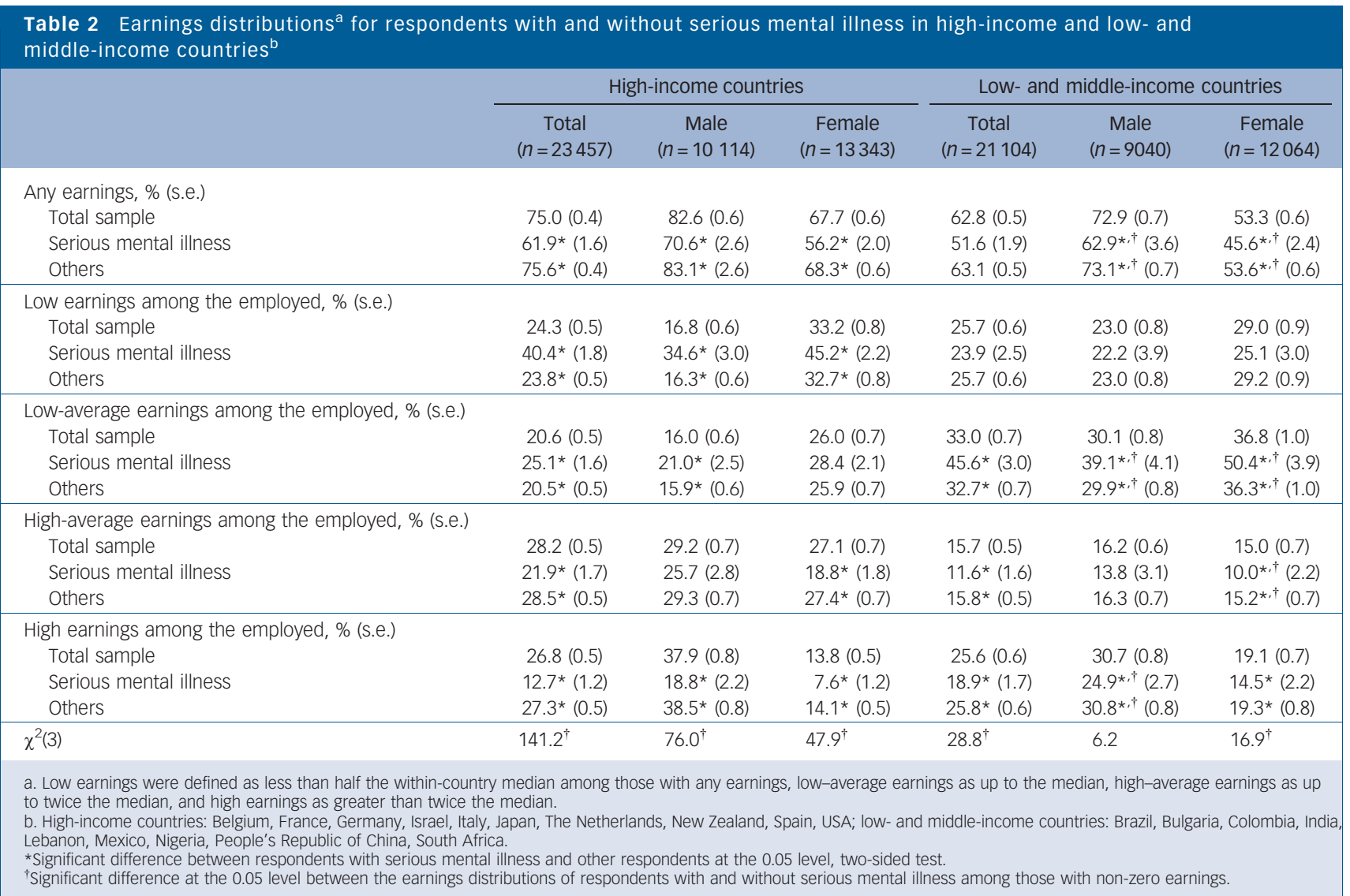

$P<0.001)$ and low- and middle-income $(51.6 \%$ v. $63.1 \%, t=5.9$, $P<0.001$ ) countries (Table 2). Similar differences are found when we look separately at males $(t=4.8-2.8, P \leqslant 0.001-0.005)$ and females $(t=5.9-3.2, P \leqslant 0.001)$. These overall differences are because of the proportions of respondents with low and low-average earnings being significantly higher among those with than those without serious mental illness in both high-income $(40.4 \% v$. $23.8 \%, t=9.0, P<0.001$ low earnings; $25.1 \%$ v. $20.5 \%, t=2.8$, $P=0.005$ low-average earnings) and low- and middle-income (low-average only; $45.6 \%$ v. 32.7\%, $t=4.4, P<0.001$ ) countries and the proportions of respondents with high-average and high incomes being significantly higher among those without than those with serious mental illness in both high-income $(28.5 \% v$. $21.9 \%, t=3.7, P<0.001$ high-average earnings; $27.3 \%$ v. $12.7 \%$, $t=11.2, P<0.001$ high earnings) and low- and middle-income (15.8\% v. 11.6\%, $t=2.5, P=0.013$ high-average earnings; $25.8 \%$ v. $18.9 \%, t=3.8, P<0.001$ high earnings) countries. Similar patterns are found when we look separately at men and women.

\section{Individual-level regression models of the association between serious mental illness and earnings}

The model-based simulations estimate that serious mental illness is associated with a reduction in earnings equal to $32 \%$ of the median within-country earnings in high-income countries and $33 \%$ of median within-country earnings in low- and middleincome countries (Table 3). The association is considerably larger among men than women in high-income countries (53\% v. 19\%, $t=4.8, P<0.001)$ but more comparable for men and women in low- and middle-income countries $(29 \%$ v. 35\%, $t=0.2$, $P=0.85)$. Decomposition shows that $39 \%$ of the total association between serious mental illness and earnings in high-income countries and $27 \%$ in low- and middle-income countries is as a result of the reduced probability of having any earnings among people with serious mental illness. This component is smaller for men than women in high-income countries (31\% v. 55\%, $t=2.4, P=0.020)$ but larger for men than women in low- and middle-income countries ( $50 \% v .18 \%, t=0.5, P=0.60)$. A larger component of the total association, $49 \%$ of the total in highincome countries and $66 \%$ in low- and middle-income countries, is as a result of the lower mean level of earnings among people with than without serious mental illness who have any earnings. This component is larger for men than women in high-income countries (56\% v. 36\%, $t=2.1, P=0.030)$ but larger for women than men in low- and middle-income countries $(75 \%$ v. $45 \%$, $t=0.5, P=0.61)$.

\section{Country-specific, individual-level and societal-level projections}

It is instructive to compare results across countries and to put the individual-level estimates into perspective by considering them in their natural metrics projected to the societal level. This was done by estimating the coefficients in the best-fitting model separately in each of the 20 surveys, expressing the estimates in terms of mean rather than median earnings, multiplying these estimates by the prevalence of serious mental illness, and then multiplying this product by the population size of the country in the age range of the sample to obtain societal-level estimates (Table 4). Serious mental illness is associated with a reduction in earnings in all 19 countries, with a statistically significant weighted average value of $19.4 \%$ of mean earnings in high-income countries and $10.9 \%$ of mean earnings in low- and middle-income countries. Between-country differences in these individual-level estimates are not significant either in high-income $\left(\chi^{2}(9)=8.1, P=0.52\right)$ or low- and middle-income $\left(\chi^{2}(9)=5.5, P=0.79\right)$ countries. At 
Table 3 The simulated associations of serious mental illness with reduced earnings at the individual level among men and women separately in high-income and low- and middle-income countries ${ }^{a}$

Estimate (s.e.)

\begin{tabular}{|c|c|c|c|c|c|c|}
\hline & \multicolumn{6}{|c|}{ Estimate (s.e.) } \\
\hline & \multicolumn{3}{|c|}{ High-income countries } & \multicolumn{3}{|c|}{ Low- and middle-income countries } \\
\hline & Total & Male & Female & Total & Male & Female \\
\hline \multicolumn{7}{|l|}{$\begin{array}{l}\text { Overall association } \\
\text { Association between serious mental illness } \\
\text { and earnings in the total sample }\end{array}$} \\
\hline $\begin{array}{l}\text { Component effects } \\
\text { Effect of serious mental illness on probability } \\
\text { of non-zero earnings } \\
\text { Estimated effect of serious mental illness } \\
\text { on earnings given non-zero earnings }{ }^{\mathrm{b}}\end{array}$ & $0.14^{*}(0.02)$ & $0.16^{*}(0.02)$ & $0.14^{*}(0.02)$ & $0.05(0.03)$ & $0.07(0.05)$ & $0.05(0.04)$ \\
\hline \multicolumn{7}{|l|}{ Decomposition of overall effect ${ }^{d}$} \\
\hline Due to difference in probability of non-zero earnings & $0.39 *(0.05)$ & $0.31 *(0.06)$ & $0.55^{\star}(0.08)$ & $0.27(0.19)$ & $0.50(0.58)$ & $0.18(0.18)$ \\
\hline Due to difference in earnings given non-zero earnings & $0.49 *(0.05)$ & $0.56^{*}(0.07)$ & $0.36 *(0.07)$ & $0.66^{*}(0.20)$ & $0.45(0.53)$ & $0.75^{*}(0.23)$ \\
\hline Due to the interaction between the two components & $0.12^{*}(0.01)$ & $0.13^{*}(0.02)$ & $0.09 *(0.02)$ & $0.07 *(0.03)$ & $0.05(0.06)$ & $0.08(0.06)$ \\
\hline \multicolumn{7}{|c|}{$\begin{array}{l}\text { a. High-income countries: Belgium, Germany, Israel, Italy, Japan, The Netherlands, Spain, USA, New Zealand; low- and middle-income countries: Brazil, Bulgaria, Colombia, India, } \\
\text { Lebanon, Mexico, Nigeria, People's Republic of China, South Africa. } \\
\text { b. The estimates reported in these rows summarise the results of individual-level simulations based on the coefficients in the best-fitting multiple regression model. (The coefficients } \\
\text { from these models are not reported here, but are available from the authors.) That model was a generalised linear model that assumed a logarithmic link function between } \\
\text { predictors and the outcome with prediction error variance proportional to the predicted values. A discussion of generalised linear model estimation is presented elsewhere. } \\
\text { simulation used the model coefficients to predict individual-level earnings twice for each respondent, once using the actual characteristics of the respondent and a second time } \\
\text { based on the counterfactual assumption that none of the respondents had serious mental illness. Individual-level differences between these earnings estimates were averaged } \\
\text { across all respondents with serious mental illness to estimate the expected mean individual-level decrease in earnings associated with serious mental illness in Part I of the current } \\
\text { table. Standard errors were obtained by replicating the entire analysis in pseudo-samples using the method of jackknife repeated replication and using the distribution of estimates } \\
\text { to generate an empirical estimate of the standard error. } \\
\text { c. The estimates reported in this row summarise the results of logistic regression analysis to predict any earnings } v \text {. no earnings. } \\
\text { d. Demographic rate standardisation } n^{27} \text { was then used to decompose the societal-level estimates into components due to the associations of serious mental illness with probability } \\
\text { of having any earnings and with the amount earned by those with any earnings. A description of this method is presented elsewhere. } \\
\text { * Significant at the } 0.05 \text { level, two-sided test. }\end{array}$} \\
\hline
\end{tabular}

the societal level, the estimate averages $0.8 \%$ of all national earnings in high-income countries and $0.3 \%$ of all national earnings in low- and middle-income countries. Between-country differences are statistically significant in high-income countries $\left(\chi^{2}(9)=30.4, P<0.001\right)$, with much lower estimates in Italy, Japan and Spain $(0.0-0.3 \%)$ than the other countries $(0.7-1.7 \%)$. Between-country differences in the societal-level estimates are not statistically significant, in comparison, in low- and middle-income countries $\left(\chi^{2}(9)=4.7, P=0.86\right)$.

\section{Discussion}

\section{Main findings}

We found that serious mental illness is associated with a reduction in population-level earnings equivalent to $0.8 \%$ of all earnings in high-income countries and $0.3 \%$ of all earnings in low- and middle-income countries. We are aware of no other comparable studies of the societal costs of mental disorders with which these estimates can be compared with other than US studies that are broadly consistent with the results reported here for the US WMH sample. ${ }^{30,31}$ An excellent benchmark for putting these values into perspective is the recent US government stimulus package in the American Recovery and Reinvestment Act (ARRA; www.recovery.gov), an unprecedented series of US government investments in education, energy, healthcare and national infrastructure implemented in an effort to stimulate the flagging US economy. The $0.8 \%$ decrement in societal-level earnings associated with serious mental illness in high-income countries is roughly equivalent to the total planned ARRA investment in national infrastructure, whereas the $0.3 \%$ decrement in societallevel earnings associated with serious mental illness in low- and middle-income countries is roughly equivalent to the total planned ARRA investment in all of healthcare. These comparisons make it clear that mental disorders are associated with massive losses of productive human capital not only at the individual level
(32-33\% of median national earnings, $11-19 \%$ of mean national earnings) but also at the societal level in the WMH countries.

\section{Implications}

This finding of a strong association between mental disorders and low earnings adds to a growing body of evidence that the impaired functioning associated with mental disorders carries an enormous societal burden. ${ }^{12,14}$ Comparative cost-of-illness studies suggest that the magnitude of this burden at the individual level is higher than that of many other classes of illness. For example, another recent $\mathrm{WMH}$ report showed that mental disorders are associated with higher levels of individual-level disability than any of the wide variety of commonly occurring physical disorders examined in the WMH surveys, including arthritis, asthma, cancer, diabetes and heart disease. ${ }^{32}$ This pattern held in both high-income and low- and middle-income countries. Health policy makers need to be made aware of these comparative illness burden data along with information about comparative treatment effectiveness to help guide decisions about resource allocation in disorder-specific screening and treatment programmes.

Controlled intervention trials have shown that employment rates and earnings among the employed can both be increased among people with severe-persistent mental illness, the vast majority of whom have a history of psychosis, using such methods as prevocational training and supported employment. ${ }^{33,34}$ It is important to note, though, that only a minority of people with serious mental illness have severe-persistent mental illness. ${ }^{35}$ Little is known about the effects of treatment on occupational outcomes among the much larger proportion of people with serious mental illness who do not have severe-persistent mental illness, the majority of whom suffer from chronic anxiety or behaviour disorders or recurrent depression. The fact that low earnings among people who have earnings accounts for a larger component of the total effect of serious mental illness on earning than having no earnings raises the question whether out-patient interventions 


\begin{tabular}{|c|c|c|c|c|c|c|c|c|c|c|}
\hline & \multirow{2}{*}{\multicolumn{2}{|c|}{$\begin{array}{c}\begin{array}{c}\text { Serious mental } \\
\text { illness }\end{array} \\
\text { Prevalence } \\
\end{array}$}} & \multicolumn{4}{|c|}{$\begin{array}{l}\text { The associations expressed as a proportion } \\
\text { of mean national earnings }{ }^{a}\end{array}$} & \multicolumn{4}{|c|}{ The associations expressed in local currency ${ }^{\mathrm{b}}$} \\
\hline & & & \multicolumn{2}{|c|}{ Individual-levelc } & \multicolumn{2}{|c|}{ Societal-level $^{\mathrm{d}}$} & \multicolumn{2}{|c|}{ Individual-level } & \multicolumn{2}{|c|}{ Societal-level (in Billions) } \\
\hline & $\%$ & (s.e.) & Estimate & (s.e.) & Estimate & (s.e.) & Estimate & (s.e.) & Estimate & (s.e.) \\
\hline \multicolumn{11}{|l|}{ High-income } \\
\hline Belgium & 4.9 & $(1.0)$ & 27.3 & (17.3) & 1.3 & $(0.8)$ & 211807 & (135 679) & 65.8 & $(42.2)$ \\
\hline France & 3.8 & $(0.5)$ & $38.9^{*}$ & (18.7) & $1.5^{*}$ & $(0.7)$ & $42660 *$ & $(20473)$ & $56.7^{*}$ & (27.0) \\
\hline Germany & 2.7 & $(0.5)$ & 36.8 & $(36.8)$ & 1.0 & $(1.0)$ & 11908 & $(11886)$ & 16.8 & $(16.7)$ \\
\hline Israel & 3.7 & $(0.3)$ & $23.8^{*}$ & $(10.0)$ & $0.9^{*}$ & $(0.4)$ & $1516^{*}$ & (622) & $0.2^{*}$ & $(0.0)$ \\
\hline Italy & 1.3 & $(0.2)$ & 1.5 & $(7.9)$ & 0.0 & $(0.1)$ & 409686 & (2 107357) & 194.1 & (998.7) \\
\hline Japan & 1.2 & $(0.4)$ & 19.1 & $(30.0)$ & 0.2 & $(0.4)$ & 611752 & (959 881) & 5.4 & $(8.7)$ \\
\hline The Netherlands & 4.4 & $(0.7)$ & $16.2^{*}$ & $(6.2)$ & $0.7^{*}$ & $(0.3)$ & $7404^{*}$ & (2901) & $3.5^{*}$ & (1.4) \\
\hline New Zealand & 4.9 & $(0.3)$ & 25.3 & (15.5) & 1.3 & $(0.8)$ & 10031 & (6275) & 1.2 & (1.3) \\
\hline Spain & 1.9 & $(0.3)$ & 18.0 & (15.2) & 0.3 & $(0.3)$ & 353356 & (294 691) & 177.2 & $(147.6)$ \\
\hline United States & 6.5 & $(0.4)$ & $25.5^{\star}$ & $(6.5)$ & $1.7^{*}$ & $(0.4)$ & $8519 *$ & $(2100)$ & $99.5^{\star}$ & $(24.6)$ \\
\hline \multicolumn{11}{|l|}{ Low- and middle-income } \\
\hline Brazil & 9.3 & $(0.7)$ & 1.5 & $(2.5)$ & 0.1 & $(0.2)$ & 17 & (30) & 0.0 & $(0.0)$ \\
\hline Bulgaria & 1.5 & $(0.3)$ & 26.6 & $(18.7)$ & 0.4 & $(0.3)$ & 638 & (441) & 0.0 & $(0.0)$ \\
\hline Colombia & 4.1 & $(0.4)$ & 20.1 & (13.0) & 0.8 & $(0.5)$ & 1051625 & (675 762) & 1042.9 & (670.3) \\
\hline India (Pondicherry) & 1.0 & $(0.2)$ & 39.4 & $(125.9)$ & 0.4 & (1.3) & 17478 & $(55715)$ & $0.1^{*}$ & $(0.0)$ \\
\hline Lebanon & 4.1 & $(0.7)$ & 2.1 & (1.1) & $0.1^{*}$ & $(0.0)$ & $141^{*}$ & $(70)$ & 0.0 & $(0.0)$ \\
\hline Mexico & 2.3 & $(0.2)$ & 5.9 & (4.6) & 0.1 & $(0.1)$ & 2022 & (1622) & 2.4 & (1.5) \\
\hline Nigeria & 0.5 & $(0.2)$ & 34.5 & $(56.5)$ & 0.2 & $(0.3)$ & 23599 & (38745) & 7.5 & $(12.4)$ \\
\hline $\begin{array}{l}\text { People's Republic of China } \\
\text { (Beijing, Shanghai) }\end{array}$ & 0.6 & $(0.2)$ & 28.9 & $(57.4)$ & 0.2 & $(0.3)$ & 413 & (826) & 0.0 & $(0.0)$ \\
\hline Shenzhen & 0.9 & $(0.3)$ & 3.6 & $(10.9)$ & 0.0 & $(0.1)$ & 1141 & (3413) & 0.0 & $(0.0)$ \\
\hline South Africa & 3.3 & $(0.3)$ & 18.8 & (22.3) & 0.6 & $(0.7)$ & 4798 & (5585) & 3.9 & (4.8) \\
\hline \multicolumn{11}{|l|}{ Pooled } \\
\hline High-income & 4.3 & $(0.1)$ & $19.4^{*}$ & (1.8) & $0.8^{*}$ & $(0.1)$ & & & & \\
\hline Low- and middle-income & 3.1 & $(0.1)$ & $10.9^{*}$ & (4.6) & $0.3^{*}$ & $(0.1)$ & & & & \\
\hline \multicolumn{11}{|c|}{$\begin{array}{l}\text { a. Results are expressed here in terms of mean earnings, whereas they were expressed in terms of median earnings in Table } 3 \text {. The median was used in estimating the models in } \\
\text { Table } 3 \text { because this transformation was considered the one that makes most sense as the basis for constraining model coefficients to be constant across countries. The mean } \\
\text { is used here, in comparison, because it is the natural metric for interpreting the substantive meaning of results. To clarify the interpretation: if } 4.3 \% \text { of respondents in high-income } \\
\text { countries have serious mental illness and serious mental illness is associated with a } 19.4 \% \text { reduction in earnings, then this level of loss in this segment of the population represents } \\
0.194 \times 0.043=0.8 \% \text { of all national earnings. } \\
\text { b. The local currencies are francs in Belgium, francs in France, marks in Germany, shekels in Israel, lira in Italy, yen in Japan, guilders in The Netherlands, dollars in New Zealand, } \\
\text { pesetas in Spain, dollars in the USA, reals in Brazil, lev in Bulgaria, pesos in Colombia, rupees in India, pounds in Lebanon, pesos in Mexico, naira in Nigeria, yuan in People's } \\
\text { Republic of China, and rand in South Africa. } \\
\text { c. Estimates do not differ significantly across either high-income countries }\left(\chi^{2}(9)=8.1, P=0.52\right) \text { or low-and middle-income countries }\left(\chi^{2}(9)=5.5, P=0.79\right) \text { based on design-based } \\
\text { Wald } \chi^{2} \text {-tests. } \\
\text { d. Estimates differ significantly across high-income countries }\left(\chi^{2}(9)=30.4, P<0.001\right) \text { but not low- and middle-income countries }\left(\chi^{2}(9)=4.7, P=0.86\right) \text { based on design-based } \\
\text { Wald } \chi^{2} \text {-tests. }\end{array}$} \\
\hline
\end{tabular}

for employed people with a serious mental illness, but one that is a non-severe-persistent mental illness, might be a useful remedy. A handful of controlled studies have documented that such interventions can reduce job loss and sickness absence, ${ }^{36,37}$ but we are aware of no controlled intervention studies that have documented an effect on earnings among the employed. Longterm follow-up would likely be required to document such an effect. A useful preliminary step might be to examine naturalistic longitudinal data to increase our understanding of the occupational career dynamics associated with serious mental illness that is non-severe-persistent mental illness in nature and the extent to which the high unemployment rate of people with serious mental illness is as a result of a high long-term unemployment rate versus a high short-term circulating unemployment rate. Intervention implications differ depending on the mix of these two kinds of unemployment, which cannot be distinguished with the data examined here.

\section{Limitations}

This study has a number of limitations in measurement, including that mental disorders were assessed with fully structured lay interviews rather than clinical interviews, that earnings were assessed with self-report rather than administrative records, that missing income reports were based on mean imputations, and that results were pooled across samples that varied in inclusion criteria and response rates. Bias could be introduced by any of these measurement characteristics. A limitation of a more conceptual sort is that the productive labour of women in domestic activities was not assigned a monetary value even though it clearly has value. In a related way, the productive labour of individuals who receive compensation for their labour in the form of goods or services (e.g. food and housing) rather than money, such as subsistence farmers, is underestimated in our analysis because we did not measure labour directly but rather inferred the existence of labour from earning. This limitation could be of special importance in low- and middle-income countries, as a larger proportion of workers are in the informal sector than in high-income countries. ${ }^{38}$ This limitation might explain the fact that estimates of gender differences are less pronounced in low- and middle-income than high-income countries.

Limitations also existed in the analysis approach, most notably that a dynamic association was estimated with cross-sectional data. The most significant implication of this fact was that we were unable to adjust for the effect of low earnings on risk of mental disorder. There is good reason to believe that such a reciprocal 
effect exists. ${ }^{39}$ Because of this limitation, although we can state that serious mental illness is associated with low earnings we cannot say that this association is the result of serious mental illness causing low earnings. Virtually all cost-of-illness studies ${ }^{9}$ have this same limitation. There is no definitive way to correct estimates for this limitation with non-experimental data. Controlling for mediating variables, such as education and marital status, which might themselves be reciprocally related to mental disorders, is not a corrective, as this can lead to overcorrection. Longitudinal analysis can sometimes help. For example, a 5-year longitudinal follow-up of 5000 initially employed respondents aged 18-30 in the Cardia study in four US cities found that high baseline depression symptom scores significantly predicted subsequent unemployment and decreases in income even after controlling for baseline education, marital status and history of prior unemployment. ${ }^{40}$ Even here, though, high baseline depression symptom scores could have been influenced by knowledge of job insecurity that turned out to predict subsequent job loss.

Sophisticated statistical models can sometimes be used to reduce the range of uncertainty about reciprocal influences if information is available on third variables that influence one but not the other variable in a reciprocal pair ${ }^{41}$ or if other assumptions can reasonably be made to justify the assumption of implicit conditional randomisation, ${ }^{42}$ but such models are highly sensitive to misspecification. As a result, experimental interventions are ultimately the only reliable way to resolve the uncertainty about the causal effects of mental disorders on earnings. Controlled studies of these sorts, when combined with information about the prevalence and course of illness from epidemiological studies, provide the greatest hope of obtaining more definitive data about the effects of serious mental illness on earnings and other aspects of productive role functioning.

\footnotetext{
Daphna Levinson, PhD, Ministry of Health, Mental Health Services, Jerusalem, Israel; Matthew D. Lakoma, MPH, Maria Petukhova, PhD, Harvard Medical School, Matthew D. Lakoma, MPH, Maria Petukhova, PhD, Harvard Medical School,
Department of Health Care Policy, Boston, USA; Michael Schoenbaum, PhD, Department of Health Care Policy, Boston, USA; Michael Schoenbaum, PhD,
National Institute of Mental Health, Bethesda, USA; Alan M. Zaslavsky, PhD, Harvard Medical School, Department of Health Care Policy, Boston, USA; Matthias Angermeyer, MD, PhD, Center for Public Mental Health, Goesing am Wagram, Austria; Guilherme Borges, $\mathrm{SCD}$, Instituto Nacional de Psiquiatria Ramon de la Fuente, Tlalpan, Mexico; Ronny Bruffaerts, PhD, Katholieke Universiteit Leuven, Leuven, Belgium; Giovanni de Girolamo, MD, IRCCS Fatebenefratelli, Brescia, Lombardy, Italy; Ron de Graaf, PhD, MSc, Netherlands Institute of Mental Health and Lombardy, Italy; Ron de Graaf, PhD, MSc, Netherlands Institute of Mental Health and
Addiction, Utrecht, The Netherlands; Oye Gureje, MD, PhD, FRCPsych, University of Ibadan, Department of Psychiatry, Ibadan Oyo, Nigeria; Josep Maria Haro, MD, MPH PhD, Parc Sanitari Sant Joan de Déu, CIBERSAM, Barcelona, Spain; Chiyi Hu, MD, PhD, Shenzhen Institute of Mental Health, Guangdong; China; Aimee N. Karam, PhD Department of Psychiatry and Clinical Psychology, Saint George Hospital University Medical Center, Department of Psychiatry and Clinical Psychology, Balamand University Medical School and the Institute for Development, Research, Advocacy and Applied Care (IDRAAC), Beirut, Lebanon; Norito Kawakami, MD, Graduate School of Medicine, University of Tokyo, Japan; Sing Lee, FRCPsych, The Chinese University of Hong Kong, Prince of Wales Hospital, Hong Kong, China; Jean-Pierre Lepine, MD, HDR, INSERM U 705, University Paris Diderot, Hôpital Lariboisière Fernand Widal, Paris France; Mark Oakley Browne, PhD, FRANZCP, Discipline of Psychiatry, School of Medicine, University of Tasmania, Tasmania, Australia; Michail Okoliyski, PhD, Department Global Mental Health, National Centre of Public Health Protection, Sofia, Bulgaria; José Posada-Villa, MD, Asesor Atención Psicosocial y Salud Mental, OIMCOLOMBIA, Bogota, Colombia; Rajesh Sagar, MD, All India Institute of Medical Sciences (AllMS), New Delhi, India; Maria Carmen Viana, MD, PhD, Section of Psychiatric Epidemiology, Institute of Psychiatry, School of Medicine, University of São Paulo, São Paulo, Brazil; David R. Williams, MPH, PhD, Harvard School of Public Health, Department of Society, Human Development and Health, Boston, USA: Ronald C. Kessler, PhD, Harvard Medical School, Department of Health Care Policy, Boston, USA
}

Correspondence: Ronald C. Kessler, PhD, Department of Health Care Policy, Harvard Medical School, 180 Longwood Avenue, Boston, MA 02115, USA. Email: kessler@hcp.med.harvard.edu

First received 1 Oct 2009, final revision 18 Mar 2010, accepted 27 Apr 2010

\section{Funding}

This paper was prepared under the auspices of the World Health Organization World Mental Health (WMH) Survey Initiative. These activities were supported by the United States
National Institute of Mental Health (NIMH; R01MH070884), the Mental Health Burden Study: Contract number HHSN271200700030C, the John D. and Catherine T. MacArthur Foundation, the Pfizer Foundation, the US Public Health Service (R13-MH066849, R01MH069864, and R01 DA016558), the Fogarty International Center (FIRCA R03-TW006481), the Pan American Health Organization (PAHO), the Eli Lilly \& Company Foundation, Ortho-McNeil Pharmaceutical Inc, GlaxoSmithKline, Bristol-Myers Squibb, and Shire. The São Paulo Megacity Mental Health Survey is supported by the State of São Paulo Research Foundation (FAPESP) Thematic Project Grant 03/00204-3. The Epidemiological survey in Bulgaria (EPIBUL) as part of the WMH is supported by the Ministry of Health of Bulgaria in the frame of the National Program for Mental Health 2001-2006. The Chinese WMH Survey Initiative is supported by the Pfizer Foundation. The Shenzhen Mental Health Survey is supported by the Shenzhen Bureau of Health and the Shenzhen Bureau of Science, Technology, and Information. The Colombian National Study of Mental Health (NSMH) is supported by the Ministry of Social Protection. The ESEMED project is funded by the European Commission (Contracts QLG5-1999-01042; SANCO 2004123), the Piedmont Region (Italy), Fondo de Investigación Sanitaria, Instituto de Salud Carlos III, Spain (FIS 00/ 0028), Ministerio de Ciencia y Tecnología, Spain (SAF 2000-158-CE), Departament de Salut, Generalitat de Catalunya, Spain, Instituto de Salud Carlos III (CIBER CB06/02/0046, RETICS RD06/0011 REM-TAP), and other local agencies and by an unrestricted educational grant from GlaxoSmithKline. The WMHI was funded by WHO (India) and helped by Dr R Chandrasekaran, JIPMER. The Israel National Health Survey is funded by the Ministry of Health with support from the Israel National Institute for Health Policy and Health Services Research and the National Insurance Institute of Israel. The World Mental Health Japan (WMHJ) Survey is supported by the Grant for Research on Psychiatric and Neurological Diseases and Mental Health (H13-SHOGAl-023, H14-TOKUBETSU-026, H16-KOKORO-013) from the Japan Ministry of Health, Labour and Welfare. The Lebanese National Mental Health Survey (LEBANON) is supported by the Lebanese Ministry of Public Health, the WHO (Lebanon), Fogarty International, anonymous private donations to IDRAAC, Lebanon, and unrestricted grants from Janssen Cilag, Eli Lilly, GlaxoSmithKline, Roche, and Novartis. The Mexican National Comorbidity Survey (MNCS) is supported by The National Institute of Psychiatry Ramon de la Fuente (INPRFMDIES 4280) and by the National Council on Science and Technology (CONACYT-G30544- H), with supplemental support from PAHO. Te Rau Hinengaro: The New Zealand Mental Health Survey (NZMHS) is supported by the New Zealand Ministry of Health, Alcohol Advisory Council, and the Health Research Council. The Nigerian Survey of Mental Health and Wellbeing (NSMHW) is supported by the WHO (Geneva), the WHO (Nigeria), and the Federal Ministry of Health, Abuja, Nigeria. The South Africa Stress and Health Study (SASH) is supported by the US NIMH (R01-MH059575) and National Institute of Drug Abuse (NIDA) with supplemental funding from the South African Department of Health and the University of Michigan. The US National Comorbidity Survey Replication (NCS-R) is supported by the NIMH (U01-MH60220) with supplemental support from the NIDA, the Substance Abuse and Mental Health Services Administration (SAMHSA), the Robert Wood Johnson Foundation (Grant 044708) and the John W. Alden Trust.

\section{Acknowledgements}

We thank the World Mental Health (WMH) Survey Initiative staff for assistance with instrumentation, fieldwork, and data analysis. A complete list of WMH publications can be found at http://www.hcp.med.harvard.edu/wmh/.

\section{References}

1 Murray CIL, Lopez AD. The Global Burden of Disease: A Comprehensive Assessment of Mortality and Disability from Diseases, Injuries and Risk Factors in 1990 and Projected to 2020. Harvard University Press, 1996.

2 Gabriel P, Liimatainen MR. Mental Health in the Workplace. International Labour Office, 2000.

3 Zhang $X$, Zhao $X$, Harris A. Chronic diseases and labour force participation in Australia. J Health Econ 2009, 28: 91-108.

4 Chatterji P, Alegria M, Lu M, Takeuchi D. Psychiatric disorders and labor market outcomes: evidence from the National Latino and Asian American Study. Health Econ 2007; 16: 1069-90.

5 Kessler RC, Heeringa S, Lakoma MD, Petukhova M, Rupp AE, Schoenbaum M, et al. Individual and societal effects of mental disorders on earnings in the United States: results from the national comorbidity survey replication. Am J Psychiatry 2008; 165: 703-11.

6 Kessler RC, Frank RG. The impact of psychiatric disorders on work loss days. Psychol Med 1997; 27: 861-73.

7 Kessler RC, Barber C, Birnbaum HG, Frank RG, Greenberg PE, Rose RM, et al. Depression in the workplace: effects on short-term disability. Health Aff (Millwood) 1999; 18: 163-71.

8 Berndt ER, Finkelstein SN, Greenberg PE, Howland RH, Keith A, Rush AJ, et al. Workplace performance effects from chronic depression and its treatment. $J$ Health Econ 1998; 17: 511-35.

9 Tarricone R. Cost-of-illness analysis. What room in health economics? Health Policy 2006; 77: 51-63.

10 Kessler RC, Aguilar-Gaxiola S, Alonso J, Angermeyer MC, Anthony JC, Brugha TS, et al. Prevalence and severity of mental disorders in the world mental health survey initiative. In The WHO World Mental Health Surveys: Global Perspectives on the Epidemiology of Mental Disorders (eds RC Kessler, TB Üstün): 534-40. Cambridge University Press, 2008.

11 Shiels C, Gabbay MB, Ford FM. Patient factors associated with duration of certified sickness absence and transition to long-term incapacity. $\mathrm{Br} J \mathrm{Gen}$ Pract 2004; 54: 86-91. 
12 World Bank. Data \& Statistics, Country Groups by Income. World Bank, 2009 (http://data.worldbank.org/about/country-classifications/country-and-lending-groups).

13 Heeringa SG, Wells EJ, Hubbard F, Mneimneh ZN, Chiu WT, Sampson NA, et al. Sample designs and sampling procedures. In The WHO World Mental Health Surveys: Global Perspectives on the Epidemiology of Mental Disorders (eds RC Kessler, TB Üstün): 14-32. Cambridge University Press, 2008.

14 Pennell B-E, Mneimneh Z, Bowers A, Chardoul S, Wells JE, Viana MC, et al. Implementation of the World Mental Health Surveys. In The WHO World Mental Health Surveys: Global Perspectives on the Epidemiology of Mental Disorders (eds RC Kessler, TB Üstün): 33-57. Cambridge University Press, 2008.

15 Kessler RC, Üstün TB. The World Mental Health (WMH) Survey Initiative Version of the World Health Organization (WHO) Composite International Diagnostic Interview (CIDI). Int J Methods Psychiatr Res 2004; 13: 93-121.

16 American Psychiatric Association. Diagnostic and Statistical Manual of Mental Disorders (4th edn) (DSM-IV). APA, 1994.

17 World Health Organization. The ICD-10 Classification of Mental and Behavioural Disorders: Clinical Descriptions and Diagnostic Guidelines. WHO, 1992.

18 First MB, Spitzer RL, Gibbon M, Williams JBW. Structured Clinical Interview for DSM-IV Axis I Disorders, Research Version, Non-patient Edition (SCID-I/NP). Biometrics Research, New York State Psychiatric Institute, 2002.

19 Demyttenaere K, Bruffaerts R, Posada-Villa J, Gasquet I, Kovess V, Lepine JP, et al. Prevalence, severity, and unmet need for treatment of mental disorders in the World Health Organization World Mental Health Surveys. JAMA 2004; 291: 2581-90.

20 Leon AC, Olfson M, Portera L, Farber L, Sheehan DV. Assessing psychiatric impairment in primary care with the Sheehan Disability Scale. Int J Psychiatry Med 1997; 27: 93-105

21 Rice DP, Miller LS. Health economics and cost implications of anxiety and other mental disorders in the United States. Br J Psychiatry 1998: 173 (supp 34): 4-9.

22 Duan N, Manning W, Morris C, Newhouse J. Choosing between the sampleselection model and the multi-part model. J Bus Econ Stat 1984; 2: 283-9.

23 Manning WG. The logged dependent variable, heteroscedasticity, and the retransformation problem. J Health Econ 1998; 17: 283-95.

24 Manning WG, Mullahy J. Estimating log models: to transform or not to transform? J Health Econ 2001; 20: 461-94.

25 McCullagh P, Nelder J. Generalized Linear Models. Chapman and Hall, 1989.

26 Buntin MB, Zaslavsky AM. Too much ado about two-part models and transformation? Comparing methods of modeling Medicare expenditures. J Health Econ 2004; 23: 525-42.
27 Schempf A, Becker S. On the application of decomposition methods Am J Public Health 2006; 96: 1899.

28 Wolter KM. Introduction to Variance Estimation. Springer-Verlag, 1985.

29 Engle RF. Wald, likelihood ratio, and Lagrange multiplier tests in econometrics. In Handbook of Econometrics, Volume I (eds Z Griliches, MD Intriligator): 796-801. Elsevier, 1983.

30 Harwood H, Ameen A, Denmead G, Englert E, Fountain D, Livermore G. The Economic Cost of Mental IIIness, 1992. National Institute of Mental Health, 2000.

31 Rice DP, Kelman S, Miller LS, Dunmeyer S. The Economic Costs of Alcohol and Drug Abuse and Mental IIIness: 1985. US Department of Health and Human Services, 1990.

32 Ormel J, Petukhova M, Chatterji S, Aguilar-Gaxiola S, Alonso J, Angermeyer $\mathrm{MC}$, et al. Disability and treatment of specific mental and physical disorders across the world. Br J PSychiatry 2008; 192: 368-75.

33 Crowther RE, Marshall M, Bond GR, Huxley P. Helping people with severe mental illness to obtain work: systematic review. BMJ 2001; 322: 204-8.

34 Latimer E. Economic considerations associated with assertive community treatment and supported employment for people with severe mental illness. J Psychiatry Neurosci 2005; 30: 355-9.

35 Kessler RC, Berglund PA, Zhao S, Leaf PJ, Kouzis AC, Bruce ML, et al. The 12-month prevalence and correlates of Serious Mental Illness (SMI). In Mental Health, United States, 1996 (eds RW Manderscheid, MA Sonnenschein): 59-70. US Government Printing Office, 1996.

36 Rost $\mathrm{K}$, Smith JL, Dickinson $\mathrm{M}$. The effect of improving primary care depression management on employee absenteeism and productivity. A randomized trial. Med Care 2004; 42: 1202-10.

37 Wang PS, Simon GE, Avorn J, Azocar F, Ludman EJ, McCulloch J, et al. Telephone screening, outreach, and care management for depressed workers and impact on clinical and work productivity outcomes: a randomized controlled trial. JAMA 2007; 298: 1401-11.

38 Standing G. Economic insecurity and global casualisation: threat or promise? Soc Indic Res 2008; 88: 15-30.

39 Charles KK, Decicca P. Local labor market fluctuations and health: is there a connection and for whom? J Health Econ 2008; 27: 1532-50.

40 Whooley MA, Kiefe $\mathrm{Cl}$, Chesney MA, Markovitz JH, Matthews K, Hulley SB. Depressive symptoms, unemployment, and loss of income. The CARDIA Study. Arch Intern Med 2002; 162: 2614-20.

41 Angrist JD, Imbens GW, Rubin DB. Identification of causal effects using instrumental variables. J Am Stat Assoc 1996; 91: 444-55.

42 Rosenbaum PR. Observational Studies. Springer, 2002. 